\title{
Development of polymorphic EST-SSR markers and characterization of the autotetraploid genome of sainfoin (Onobrychis viciifolia)
}

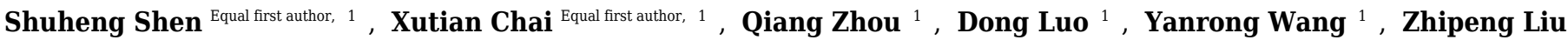 \\ Corresp. 1 \\ ${ }^{1}$ State Key Laboratory of Grassland Agro-ecosystems, Key Laboratory of Grassland Livestock Industry Innovation, Ministry of Agriculture and Rural Affairs, \\ College of Pastoral Agriculture Science and Technology, Lanzhou University, Lanzhou University, Lanzhou, Gansu, China \\ Corresponding Author: Zhipeng Liu \\ Email address: Izp@Izu.edu.cn
}

Background: Sainfoin (Onobrychis viciifolia) is a highly nutritious, tannin-containing, and tetraploid forage legume. Due to the lack of detailed transcriptomic and genomic information on this species, genetic and breeding projects for sainfoin improvement have been significantly hindered.

Methods: In this study, a total of 24,630,711 clean reads were generated from 14 different sainfoin tissues using Illumina paired-end sequencing technology and deposited in the NCBI SRA database (SRX3763386). From these clean reads, 77,764 unigene sequences were obtained and 6,752 EST-SSRs were identified using denovo assembly. A total of 2,469 primer pairs were designed, and 200 primer pairs were randomly selected to analyze the polymorphism in five sainfoin wild accessions.

Results: Further analysis of 40 sainfoin individuals from the five wild populations using 61 EST-SSR loci showed that the number of alleles per locus ranged from 4 to 15, and the expected heterozygosity varied from 0.55 to 0.91 . Additionally, by counting the EST-SSR band number and sequencing the three or four bands in one sainfoin individual, sainfoin was confirmed to be autotetraploid. This finding provides a high level of information about this plant.

Discussion: Through this study, 61 EST-SSR markers were successfully developed and shown to be useful for genetic studies and investigations of population genetic structures and variabilities among different sainfoin accessions. 


\section{Development of polymorphic EST-SSR markers and}

2 characterization of the autotetraploid genome of

3 sainfoin (Onobrychis viciifolia)

4 Shuheng Shen ${ }^{1}$, Xutian Chai ${ }^{1}$, Qiang Zhou ${ }^{1}$, Dong Luo ${ }^{1}$, Yanrong Wang ${ }^{1}$, Zhipeng

$5 \quad$ Liu Corresp 1

$6{ }^{1}$ State Key Laboratory of Grassland Agro-ecosystems, Key Laboratory of Grassland Livestock Industry Innovation,

7 Ministry of Agriculture and Rural Affairs, College of Pastoral Agriculture Science and Technology, Lanzhou

8 University, Lanzhou University, Lanzhou, Gansu, China

9

\section{Corresponding Author: Zhipeng Liu}

Email address: 1zp@1zu.edu.cn

Background: Sainfoin (Onobrychis viciifolia) is a highly nutritious, tannin-containing, and tetraploid forage legume. Due to the lack of detailed transcriptomic and genomic information on this species, genetic and breeding projects for sainfoin improvement have been significantly hindered.

Methods: In this study, a total of 24,630,711 clean reads were generated from 14 different sainfoin tissues using Illumina paired-end sequencing technology and deposited in the NCBI SRA database (SRX3763386). From these clean reads, 77,764 unigene sequences were obtained and 6,752 EST-SSRs were identified using de novo assembly. A total of 2,469 primer pairs were designed, and 200 primer pairs were randomly selected to analyze the polymorphism in five sainfoin wild accessions.

Results: Further analysis of 40 sainfoin individuals from the five wild populations using 61 EST-SSR loci showed that the number of alleles per locus ranged from 4 to 15, and the expected heterozygosity varied from 0.55 to 0.91 . Additionally, by counting the EST-SSR band number and sequencing the three or four bands in one sainfoin individual, sainfoin was reconfirmed to be autotetraploid. This finding provides a high level of information about this plant.

Discussion: Through this study, 61 EST-SSR markers were successfully developed and shown to be useful for genetic studies and investigations of population genetic structures and variabilities among different sainfoin accessions. 


\section{INTRODUCTION}

Sainfoin (Onobrychis viciaefolia) is a cross-pollinated, autotetraploid and perennial legume $(2 n=4 x=28)$ that is commonly used as a silage. The nutritional value of sainfoin is universally recognized, and it is known to be rich in proteins and secondary metabolites. Sainfoin can also fix atmospheric nitrogen through its symbiotic relationship with rhizobia. The origin center of sainfoin is known in the Middle East and Central Asia. In China, sainfoin is mainly grown in the northeast, north and northwest regions, including Gansu province. It does not cause bloat in grazing animals, and can provide palatable, high-quality forage (Bhattarai et al., 2016; Frame et al., 2005). Sainfoin contains high levels of condensed tannins that sainfoin has shown to reduce parasites in the ruminant digestive tract and provide environmental benefits by reducing methane emissions from ruminant animals (Malisch et al., 2015; Sottie et al., 2014; Surendra et al., 2018). In recent years, there was a renewed interest in sainfoin for its use in animal diets. Several studies indicated that the voluntary intake of sainfoin by grazing heifers is higher than alfalfa (Medicago sativa) (Parker and Moss, 1981; Kempf et al., 2016). Scharenberg and colleagues reported that sainfoin was more palatable than birdsfoot trefoil when given to sheep (Scharenberg et al., 2007). However, sainfoin is a relatively understudied forage legume compared to alfalfa or clovers (Trifolium spp.). Therefore, exploitation and conservation of sainfoin germplasms became important. Also, knowledge of sainfoin genetic diversity and structures has become a prerequisite for successful sainfoin conservation programs (Sun et al., 2002). To date, reports on sainfoin transcriptomes and genomics are very limited, and this hinders many genetic and breeding projects for this plant.

Simple sequence repeats (SSR) for microsatellite markers are tandem repeated mono-, di-, tri-, tetra-, penta- or hexa-nucleotide sequences that possess high information content, codominance and locus specificities and are easier to be detected compared to other molecular markers. SSR markers were successfully used to study genetic variation, genetic mapping, and molecular breeding for many plants (Mohammadreza et al., 2007; Gupta et al., 2010; Kfm et al., 2010; Prasanna et al., 2010; Li et al., 2011). Compared to genomic-SSRs, expressed sequence tag (EST) EST-SSRs were reported to provide higher levels of transferability across the related species, because EST-SSR markers were identified in the coding regions of the genome and the identified sequences are more conserved among homologous genes (Wu et al., 2014). EST-SSR markers have now been developed for many plant species using Illumina sequencing technologies. These plants include alfalfa (Liu et al., 2013a), wheat (Gupta and Varshney, 2000), adzuki bean (Yang et al., 2015), edible pea (Nisar . al., 2017), mung bean (Chen et al., 2015), and Siberian wildrye (Zhou et al., 2016). Current studies on sainfoin genetic diversity, mapbased cloning, and molecular breeding lag behind many legume crops due mainly to the lack of genomic information. Only 101 polymorphic EST-SSRs were confirmed by individual sainfoin plants (Kempf et al., 2016; Mora-Ortiz et al., 2016). The current available EST-SSR primers are not sufficient for the studies on sainfoin genetic diversity, fingerprinting, and genetic mapping. These limitations have hindered the molecular breeding for sainfoin yield and nutritional value improvements. 
71 Recent studies showed that next-generation transcriptome sequencing and Roche/454 genome

72 sequencing technologies are effective solutions for generating large-scale genomic information in short periods of time and at reasonable costs, even for non-model plant species (Wang et al., 2010). Because these sequencing technologies also allow extensive investigations on alternative RNA splicing, discovery of novel transcripts, and identifications of gene boundaries at the single-nucleotide resolution level, massive parallel transcriptome sequencing has provided great opportunities to revolutionize studies of plant transcriptomics. For example, EST-SSR markers can now be quickly developed using a bioinformatic data mining approach. Because EST-SSR markers have many advantages over genomic SSR markers during marker development, we decided to analyze the complex tetraploid sainfoin genome to develop useful EST-SSR markers for future studies. Compared with SNP markers, EST-SSRs are multi-allelic and it have a higher level of polymorphism and transferability across related species. These features make EST-SSR markers highly variable and useful for distinguishing closely related populations or varieties compared to genomic SSR markers. EST-SSR markers are known to be easily accessible, present in gene-rich regions, associated with transcription, useful for candidate gene identification, and transferrable between closely related species (Thiel et al., 2003). We considered that the ESTSSR markers developed for sainfoin using an RNA-seq technology should benefit sainfoin improvement projects, such as genetic diversity analysis, germplasm identification, comparative genetics, phylogenetic relationship, QTL analysis, linkage mapping and marker-assisted selection.

In this study, our aim was to use transcriptome sequencing of 14 sainfoin tissues on the Illumina Hiseq2500 sequencing platform. The objective of this study was to achieve a valuable sequence resource and develop some high polymorphism EST-SSR markers that would allow a better understanding of the genetic diversity of sainfoin. By counting the EST-SSR band number and sequencing the bands in sainfoin individuals, we aimed to re-verify sainfoin autotetraploidy.

\section{MATERIALS \& METHODS}

\section{Tissue sampling and total RNA isolation}

Sainfoin callus cells, emerging tidbits $(<2 \mathrm{~cm})$, young inflorescences ( 2 to $4 \mathrm{~cm}$ ), inflorescences (4 to $6 \mathrm{~cm}$ ), mature inflorescences $(6$ to $8 \mathrm{~cm}$ ), developing seed pods [16 days after pollination (dap)], mature seed pods (24 dap), roots, germinated seeds (36 hours after seed germination), young stems (less lignified), stems (moderately lignified), mature stems (highly lignified), young compound leaves, and mature compound leaves were harvested (Fig. 1). A total of 14 tissues in the Figure 1, The callus cells were induced from inflorescences at $25^{\circ} \mathrm{C}$ on solid MS medium containing 2,4-dichlorophenoxyacetic acid $(3.0 \mathrm{mg} / \mathrm{L}$ ) for 30 days under a $16 / 8 \mathrm{~h}$ (light/dark) light cycle(Ma et al., 2012). (A-G and J-N) were harvested from the same individual plant, these tissues used in this study were from the same 2-year-old plants grown inside a greenhouse set at $22^{\circ} \mathrm{C}$ and a $16 / 8 \mathrm{~h}$ (light/dark) light cycle at Lanzhou University, radicle and germ (H and I) were harvested from three seedlings germinated from seeds. The sampled tissues were immediately frozen in liquid nitrogen and stored at $-80^{\circ} \mathrm{C}$ until use. Total RNA was isolated from 14 
110

111

112

113

114

115

116

117

118

119

120

121

122

123

124

125

126

127

128

129

130

131

132

133

134

135

136

137

138

139

140

141

142

143

144

145

146

individually collected samples using the RNeasy Plant Mini Kit (Qiagen, Cat. \#74904) as instructed. Concentrations of the RNA samples were determined using a NanoDrop ND1000 spectrophotometer (Thermo Scientific, USA).

\section{cDNA library construction and sequencing}

To better elucidate tissue-specific RNA transcription, each RNA sample was adjusted to 400 $\mathrm{ng} / \mu \mathrm{L}$. Twenty micrograms of total RNA was taken from each RNA sample and pooled prior to cDNA library preparation using the mRNA-Seq Sample Preparation Kit (Illumina Inc. Beijing China). Briefly, poly (A) mRNA was isolated from the pooled total RNA sample using magnetic oligo dT beads and used to synthesize first-strand cDNA with random hexamer primers and reverse transcriptase (Invitrogen, Beijing China). Short cDNA fragments were purified using a MinElute PCR Purification Kit (Qiagen, Beijing China), resuspended in an EB buffer (Qiagen), and poly A was added. Sequencing adapters were ligated to the short cDNA fragments, and the libraries were sequenced using the Illumina HiSeq2500 sequencing platform at the BioMarker Company (Beijing, China). Processing of fluorescent images for sequence base-calling and calculation of quality values were performed using the Illumina data processing pipeline, which yielded 100-bp paired-end reads.

\section{Sequence assembly and annotation}

Before assembly, the raw reads were filtered to remove poly A/T, low-quality sequences, and empty reads or reads with more than $10 \%$ of bases having $\mathrm{Q}<30$. The assembly of a de novo transcriptome using clean reads was performed using the short-read assembling program Trinity. Contigs were generated after combining the reads with a certain degree of sequence overlap. Paired-end reads were used to detect contigs from the same transcript and the distances between contigs. Scaffolds were produced using N, representing different sequences between two contigs but connecting these two contigs together. Gaps between scaffolds were filled with paired-end reads and the reads with the lowest numbers of Ns. The resulting sequences were referred to as unigenes. The EST-SSR annotation positions of these unigenes were determined using BLASTX alignment (e-value < 10-5) against the sequences in the databases: Nr, Swiss-Prot, KEGG, COG, and unigene sequences. After $\mathrm{Nr}$ annotation, unigene $\mathrm{GO}$ annotations were conducted using the Blast2GO algorithm. GO functional classifications of the unigenes were performed using the WEGO software.

\section{Detection of EST-SSR markers and designing of primers}

EST-SSR markers were detected in the assembled unigenes using the Simple Sequence Repeat Identification Tool. The EST-SSRs were considered to contain mono-, di-, tri-, tetra-, penta-, and hexa-nucleotides with a minimum of ten, six, five, five, five, and five repeats, respectively. ESTSSR primers were designed using the BatchPrimer3 software and synthesized by the Shanghai Sangon Biological Engineering Technology (Shanghai, China).

\section{Sources of wild sainfoin populations}


147 To produce results representing a wide range of sainfoin populations, we collected 40 individual 148 wild sainfoin plants from five different locations (eight plants per location): Minqin, Jingyuan, 149 Yuzhong, Huining and Maqu (Table S3). After air drying, leaves were taken from each plant and

150

151

152

153

154

155

156

157

158

159

160

161

162

163

164

165

166

167

168

169

170

171

172

173

174

175

176

177

178

179

180

181

182

183 stored at room temperature until use.

\section{DNA extraction}

DNA was extracted from the harvested and dried leaves using the Nucleon Phytopure Genomic DNA extraction kit (Ezyp column plant genomic DNA extraction kit, Sangon Biotech Shanghai, China) on the samples described above using a protocol reported previously (Mora-Ortiz et al., 2016). The quality of each isolated genomic DNA was examined using $0.8 \%$ agarose gelelectrophoresis, and the concentration of each genomic DNA sample was determined using a NanoDrop 8000 spectrophotometer (Nanodrop Technologies Wilmington, DE). The DNA samples were diluted individually in TE buffer to $25 \mathrm{ng} \mathrm{DNA} / \mu \mathrm{L}$ prior to PCR amplification.

\section{Amplification of EST-SSRs using polymerase chain reaction (PCR)}

A total of 200 primer pairs were produced for this study and used to amplify EST-SSRs from the genomic DNA samples from the 40 wild sainfoin plants. PCR amplifications were performed in $5-\mu \mathrm{L}$ reactions $[0.5 \mu \mathrm{L}$ of DNA, $2.5 \mathrm{uL}$ of $2 \times \operatorname{mix}(\mathrm{e} . \mathrm{g}, 0.5 \mu \mathrm{L}$ of $2 \times$ PCR buffer, $1 \mu \mathrm{L}$ of $1 \mathrm{mM}$ dNTPs, $0.4 \mu \mathrm{L}$ of $25 \mathrm{mM} \mathrm{MgCl}, 0.1 \mu \mathrm{L}$ of Taq DNA polymerase $), 0.5 \mu \mathrm{L}(5 \mathrm{pmoL} / \mu \mathrm{L})$ of forward and reverse primers, and $1 \mathrm{uL}$ of sterile distilled water]. Three microliters was added to the PCR reaction in each tube, and PCR was performed using a PCR-100TM Thermal cycler set at $94^{\circ} \mathrm{C}$ for $4 \mathrm{~min}$, followed by 35 cycles of $94^{\circ} \mathrm{C}$ for 1 minat a specific annealing temperature for $30 \mathrm{~s}$ and $72^{\circ} \mathrm{C}$ for $20 \mathrm{~s}$. The final extension was at $72^{\circ} \mathrm{C}$ for $7 \mathrm{~min}$. The resulting PCR products were resolved using $8.0 \%$ non-denaturing polyacrylamide gels (Lot\# I20826, GelStain, China) after electrophoresis.

\section{Construction of $\mathbf{T}$ vectors}

Fragments of 200 to $500 \mathrm{bp}$ were PCR amplified from sainfoin genomic DNA using the genespecific primers. The PCR products were purified and these fragments were then cloned into pGEM-T Easy Vector (Promega, Madison, WI, USA ). The constructs were transferred into E.coli DH5 $\alpha$ using the freezing/heat-shock method, and sequenced by Shanghai Sangon Biological Engineering Technology using sanger dideoxy (Shanghai, China).

\section{Diversity analysis}

The observed heterozygosity (Ho) was calculated as previously shown (Liu et al., 2007), and the corrected heterozygosity (He), corrected for sample size and (PIC), and the average polymorphism information content were analyzed using the ATETRA 1.2.a software program. Only specific bands that could be unambiguously scored across all individual plants were used in this study. A clustering analysis was used to generate a dendrogram using the unweighted pairgroup method with arithmetic mean (UPGMA) and Nei's unbiased genetic distance with the NTSYSPC 2.0 software package. We used STRUCTURE 2.3.4 to generate a structure map. 
184

185

186

187

188

189

190

191

192

193

194

195

196

197

198

199

200

201

202

203

204

205

206

207

208

209

210

211

212

213

214

215

216

217

218

219

220

\section{Results}

\section{RNA sequencing and de novo assembly}

A cDNA library representing 14 different sainfoin tissues (Fig. 1) was sequenced, and a total of $26,912,927$ raw reads were obtained (Table 1). After rigorous quality checks and data filtering, a total of 24,630,711 high-quality clean reads were obtained, and about $92 \%$ of them hadquality (Q)-scores above Q30. These clean reads together contained a total of 6,264,706,761 nucleotides (nt), without N, and about $45 \%$ GC content. The high-quality reads were deposited in the U.S. National Center for Biotechnology Information (NCBI) sequence read archive (SRA) database (SRX3763386). From these high-quality reads, a total of 2,678,687 contigs with a mean length of $72.26 \mathrm{bp}$ and an N50 length of $69 \mathrm{bp}$ were generated using de novo assembly. The total number of unigenes from the paired-end reads was 77,764, and 27,437 of them had distinct clusters. A total of 50,327 unigenes had distinct singletons, and the total length of these unigenes was $53,035,704 \mathrm{bp}$. The average length of a unigene was $682.01 \mathrm{bp}$ with an N50 value of 1,209 bp. Of the 77,764 unigenes, the length of 50,327 unigenes ranged from 200 to $500 \mathrm{bp}$, the length of 22,096 unigenes ranged from 500 to $2,000 \mathrm{bp}$, and the length of 5,341 unigenes was above 2,000 bp (Table 1). Also, 36,353 of the 77,764 unigenes were successfully annotated according to the NR, Pfam, Swiss-Prot, KEGG, COG, and GO databases (Table 2), and 10,387 unigenes were assigned to COG classifications.

\section{Frequency and distribution of EST-SSRs}

A total of 6,752 potential EST-SSRs were identified in the 77,764 unigenes (Table 1) and used to design 2,469 primer pairs. Since 1,271 unigenes contained more than one EST-SSR, the types and distributions of the total 6,752 potential EST-SSRs were analyzed. As shown in Fig. S4, the density of single nucleotide repeats was the highest ( 88 of SSRs per Mb), followed by trinucleotide repeats (64 of SSRs per $\mathrm{Mb}$ ). The most abundant repeat type was the mononucleotide repeat $(2,906$ repeats or $43.04 \%$ of the total repeats), followed by tri-nucleotide repeats $(2,262,33.50 \%)$, di-nucleotide repeats $(1,287,19.06 \%)$, quad-nucleotide repeats $(263$, $3.90 \%$ ), hexa-nucleotide repeats $(19,0.28 \%)$, and penta-nucleotide repeats $(15,0.22 \%)$ (Table 3). Moreover, the EST-SSRs with five tandem repeats were the most common EST-SSRs (24.88 $\%)$, followed by ten tandem repeats $(22.07 \%)$, six tandem repeats $(16.88 \%)$, eleven tandem repeats $(10.19 \%)$, seven tandem repeats $(7.09 \%)$, and the remaining tandem repeats $(<5 \%)$ (Table 3). In addition, the GO enrichment for the 6,752 SSR-containing unigenes was done using the agriGO algorithm (http://bioinfo.cau.edu.cn/agriGO) and the 971,445 unigenes available in the database as the reference. The results of the GO enrichment analysis indicated that the proportion of the "transcription" (GO: 0003674)-related unigenes was significantly enriched (Fig. S5).

\section{Development of EST-SSR markers}

Using the SSR-containing unigene sequences, 200 primer pairs were randomly chosen from the 
221

222

223

224

225

226

227

228

229

230

231

232

233

234

235

236

237

238

239

240

241

242

243

244

245

246

247

248

249

250

251

252

253

254

255

256

257

258

259

260

2,469 identified primer pairs, synthesized, and used to determine if the EST-SSR loci identified in this study were true-to-type EST-SSR loci in the sainfoin populations. Of the 200 primer pairs, 178 of them successfully amplified fragments from sainfoin genomic DNA during PCR, while the other 22 primer pairs failed. Also, 132 of the 178 PCR primer pairs amplified products of the expected size. Using genomic DNAs from the 40 different wild sainfoin plants (Table S3) as templates, 61 of the 132 primer pairs were found to be polymorphic (Fig. S6 and Table S4) and the other 71 primer pairs were monomorphic (Table S2).

\section{Assessment of sainfoin genetic diversity}

The 61 primer pairs mentioned above were used to analyze the genetic diversity among the population comprising 40 wild sainfoin plants from five different geographic locations. The result showed that a total of 459 alleles were present in the 61 polymorphic loci in the 40 different individuals, and the number of alleles per loci ranged from three to twelve with an average number of 7.52. The Ho, He, and PIC were estimated from 0.05 to 1.0 (mean value $=$ $0.67), 0.55$ to 0.91 (mean value $=0.77)$, and 0.51 to 0.88 (mean value $=0.74)$, respectively (Table S4). These 61 polymorphic loci or EST-SSR markers are unlinked and have high degrees of universality among the assayed germplasms. Therefore, they are useful for studying biogeographic processes that shaped the current disjunctive distributions of sainfoin. Furthermore, PCR amplicons representing EST-SSRs from different sainfoin individuals were sequenced and the results showed that all of the sequenced alleles were homologous to the original locus from which the marker was designed.

Using NTSYSPC 2.0 software and the UPGMA method, obtain the dendrogram (Fig. 2). The 40 sainfoin individuals can be divided into five distinct wild populations. The individuals in population 1 originated from Minqin, the individuals in population 2 were from Jingyuan, the individuals in population 3 were from Yuzhong, the individuals in population 4 were from Huining, and the individuals in population 5 were from Maqu (Table S3). The individual plants from the Jingyuan sampling site were clues developed on cultivated was assessed on related taxa within the sainfoin genus, most of them resulted to be easily amplifiable and detectable across all genotypes, and just a few showed problems of amplification or scoring, probably due to polymorphisms (insertions/deletions or base mutations) in primer regions or regarding subsp. However, most EST-SSR markers found in this study are highly useful for discriminating related sainfoin populations or related taxa, including wild species, subspecies, and subgenera. Consequently, we propose that these EST-SSR markers can be used in future studies on comparative genomics, genetic differentiation, and evolutionary dynamics within the sainfoin genus.

Using STRUCTURE 2.3.4 to generate a structure map. STRUCTURE analysis based on 459 loci representing EST-SSRs was performed to evaluate the genetic structure of the 40 wild sainfoin individuals. The highest $\Delta \mathrm{K}$ was observed for $\mathrm{K}=6[\Delta \mathrm{K}(6)=144] . \Delta \mathrm{K}$ values for $\mathrm{K}$ $=3-5$ and $K=7$ were not significant $(\Delta K=0.078-5.632)$. The mean value of the log probability of the data was higher for $\mathrm{K}=6$ than for $\mathrm{K}=4$, and $\mathrm{K}=5$ [LnP (D) $\mathrm{K}=6=-13190.22$, $\mathrm{LnP}$ (D) $\mathrm{K}=4=-14038.11$, LnP (D) $\mathrm{K}=5=-13599$ ] (Table S6). Therefore, six clusters were chosen as 
261 the most probable genetic structure of the wild sainfoin individuals. With $K=6$, seven

262 individuals from site 1 were assigned to cluster 1 with coefficient Q values ranging from 0.782 to

263 1.000; one individual from site 2 to cluster 2 with a Q value between 0.900 and1.000; one from

264 site 2 to cluster 3 with a $Q$ value between 0.900 and 1.000;three from site 2 and three from site 3

265 to cluster 4 with Q values from 0.782 and 0.982 ; seven from site 4 to cluster 5 with Q values

266 from 0.683 to 0.973 ; and eight from site 5 to cluster 6 with Q values from 0.714 and 0.965 (Fig.

267 3). Ten sainfoin individuals could not be assigned to any of the clusters due to high levels of

268 admixture $(\mathrm{Q}<0.6)$.

269 Furthermore, PCR amplicons of Vo61 and Vo157 EST-SSRs from single individuals were

270

271

272

273

274

275

276

277

278

279

280

281

282

283

284

285

286

287

288

289

290

291

292

293

294

295

296

297

298

299

300 sequenced to check the authenticity of the SSR locus (Fig. S6 and Fig. 4). For individual 2 in accession II at the Vo61 locus, four amplicons with different AGAA repeats, (AGAA) 3 , $(\mathrm{AGAA})_{4},(\mathrm{AGAA})_{5},(\mathrm{AGAA})_{6}$, were found by pGEM-T easy vector sequencing, while three amplicons with different $\mathrm{ACC}$ repeats, $(\mathrm{ACC})_{3},(\mathrm{ACC})_{5},(\mathrm{ACC})_{6}$, were found for individual 1 in accession II for the Vo157 locus.

\section{DISCUSSION}

Transcriptome sequencing followed by de novo assembly was shown to be a useful tool for gene and molecular marker discovery in plants, animals and other organisms. Here, we showed that short reads obtained using Illumina paired-end sequencing of sainfoin cDNAs could be quickly assembled and used for transcriptome analysis, marker development and gene identification without a reference sainfoin genome. The results of our marker validation assay agreed with previous investigations on SSR markers of common bean (Schmutz et al., 2014) and SSR markers in other legume crops (Kang et al., 2014) where EST-SSR markers detect moderate polymorphism. De novo transcriptome sequencing was considered a crucial tool for gene function study and development of molecular markers (Garg et al., 2011; Kaur et al., 2012; Duarte et al., 2014; Yates et al., 2014). For legume plants, whole genome sequences of Medicago (Young et al., 2011), soybean (Schmutz et al., 2009), common bean (Schmutz et al., 2014), mung bean (Kang et al., 2014), and adzuki bean (Yang et al., 2015) were reported. In this study, the assembled unigenes were analyzed by BLAST searching the available databases, and a total of 36,353 unigenes ( $47 \%$ of the assembled unigenes) were annotated. In addition, the identity of 46 $\%$ of the assembled unigenes was obtained by BLASTX searching against the NR database, although this percentage was slightly lower than that reported for other plants, including orchid (49.25\%) (Zhang et al., 2013), sesame (53.91\%) (Wei et al., 2011), and litchi (59.65\%) (Li et al., 2013). It is possible that the current incomplete sainfoin genomic and transcriptomic information affected our annotation efficiency and left some sainfoin-specific genes unidentified.

In this study, a total of 6,752 potential EST-SSRs were identified in the 77,764 unigenes. The frequency of EST-SSRs was one SSR per 4.35-kb sequence, which is much higher than what was reported for pineapple (1 in $13 \mathrm{~kb}$ ) (Ong et al., 2012), and lotus (1 in $13.04 \mathrm{~kb})($ Pan et al., 2010). However, this frequency is lower than what was reported for Levant cotton (1 in 2.4 $\mathrm{kb}$ ) (Jena et al., 2012), castor bean (1 in $1.77 \mathrm{~kb}$ ) (Qiu et al., 2010), and radish (1 in $3.45 \mathrm{~kb}$ ) (Wang et al., 2012). It was speculated that the estimated frequency of SSRs depended strongly 
301 on the size of the database, SSR search criteria, and mining tools used (Varshney et al., 2005). In 302 our study, mono-repeats were the most abundant repeat type. Our GO enrichment analysis 303 showed that unigenes related to the category "transcription" were significantly enriched. This

304 finding agreed with our previous investigations on alfalfa and Vicia sativa using similar GO analyses of SSR-containing unigene approaches (Liu et al., 2013a; Liu et al., 2013b). The results of GO enrichment analysis of unigenes containing EST-SSR loci indicated that EST-SSR loci are not randomly distributed in the transcriptome and it preference exists in transcription factors (Fig S5C). These results are consistent with previous studies (Luo et al., 2015; Zhou et al., 2016).

The analysis of transcriptomes from 14 distinct sainfoin individuals using the Illumina HiSeqTM 2500 platform generated a total of 24.63 million clean reads, equivalent to a total of 6,264,706,761 bp length. Approximately $91.5 \%$ of the clean reads had Phred quality scores at the Q30 level and an N percentage (percentage of ambiguous " $N$ " bases) of 0 . The quality of the clean reads indicated a quality sequencing result. A total of 77,764 unigenes were assembled and had a mean unigene length of $682.01 \mathrm{bp}$. This mean length was greater than what was reported for tea (402 bp) (Tan et al., 2013) and sweet potato (581 bp) (Wang et al., 2010), possibly because the paired-end reads (100 bp) obtained in this study were longer than those (75 bp) used in previous studies (Jia et al., 2015). It is noteworthy that the 100-bp paired-end reads obtained in this study were shorter than what was documented in other reports, including alfalfa (803 bp) (Liu et al., 2013a) and seashore paspalum (970 bp) (Jia et al., 2015). Thus, the longer mean unigene length obtained in this study may also contribute to the different parameters used during sequence assembly and the nature of the plant. In addition, we thought that the Illumina sequencing technology used in this study also helped to allow better discoveries of novel unigenes and marker development for sainfoin. A neighbor-joining dendrogram based on allele distances showed the genetic relationships among the 40 sainfoin individuals (Fig. 3).

ATETRA 1.2.a software was used to calculate the number of alleles per locus, allele size, Ho, He, genetic distances, genetic similarity between individual sainfoins, and PIC defined as a closely related diversity measure. The average PIC value obtained in this study was 0.74 , which is higher than that (0.43) reported for sainfoin (Mora-Ortiz et al., 2016). The difference between the two PIC values might be caused by the different materials and different loci used in these two studies. For example, the EST-SSRs used in our study were from 14 different sainfoin tissues, but the markers used by Mora-Ortiz et al. were generated from 7-day-old seedlings. Our study focused on 40 wild sainfoin individuals, and Mora-Ortiz et al. used 32 sainfoin individuals representing distinct varieties or landraces. Additionally, the 61 highest polymorphic EST-SSR markers were selected from 200 EST-SSR primer pairs in our study.

The dendrogram and STRUCTURE map showed no clear relationship between the clustering pattern and geographical distance, which may be due to the lack of adequate accession numbers and the fact that these sainfoin accessions were sampled from adjacent areas, where the frequent exchange of sainfoin germplasm may obscure an existing pattern following the geographical origin of the accessions. In addition, this vague geographical pattern may be related to the autotetraploid characteristics of sainfoin. Therefore, the use of a higher number of accessions from close geographical locations and more individual plants per accession will be 
342

343

344

345

346

347

348

349

350

351

352

353

354

355

356

357

358

359

360

361

362

363

364

365

366

367

368

369

370

371

372

373

374

375

376

377

378

379

380

essential for verifying the genetic diversity of sainfoin in future studies.

In heterologous hexaploid wheat, there are one or two amplicons in a single individual at an SSR locus (Yang et al., 2016; Sipahi et al., 2017). The autotetraploid plants alfalfa (Liu et al., 2007) and potato (Chandel et al., 2015) show one, two, three or four amplicons in single individuals at an SSR locus. We found that the number of bands in sainfoin individuals ranges from one amplicon to four amplicons. For example, one band was found at Vo 61 in the No. 7 plant in accession II , two bands in the No. 4 plant, three bands in the No. 3 plant, and four bands in the No. 2 plant (Fig. S6). Additionally, by sequencing the four bands in the No. 2 plant, different AGAA repeats were found in the four amplicons (AGAA) $)_{3},(\mathrm{AGAA})_{4},(\mathrm{AGAA})_{5}$, (AGAA) ${ }_{6}$ (Fig. 4). In the previous study, there are some reports claimed that sainfoin is autotetraploid (Christine et al., 2013; Mora-Ortiz et al., 2016). And the sequencing results of EST-SSR alleles in our study consistent with the characteristics of autotetraploid. The results provided new evidence from EST-SSR molecular markers that sainfoin is autotetraploid.

\section{CONCLUSIONS}

In this study, a total of 24,630,711 clean reads were generated from 14 different sainfoin tissue samples using Illumina paired-end sequencing technology. The reads were deposited into the NCBI SRA database (SRX3763386). Form these clean reads, 77,764 unigene sequences were identified and resulted in 6,752 EST-SSRs. Using this information, 61 novel EST-SSR markers were developed for sainfoin and successfully used to confirm the genetic diversities among the 40 randomly collected wild sainfoin individuals, representing five different geographic regions. Additionally, sainfoin was re-verified to be autotetraploid by counting the EST-SSRs band number and sequencing the bands in one sainfoin individual. These 61 EST-SSR markers have relatively high degrees of polymorphism and can be used in studies on genetic diversity, cultivar identification, sainfoin evolution, linkage mapping, comparative genomics, and/or markerassisted selection breeding of sainfoin.

\section{REFERENCES}

Bhattarai S, Coulman B \& Biligetu B. 2016. Sainfoin (Onobrychis viciifolia): Renewed interest as a forage legume for Western Canada. Canadian Journal of Plant Science 96(5), 748-756. DOI org/10.1139/cjps-2015-0378

Chandel P, Tiwari JK, Ali N, Devi S, Sharma S, Sharma S. 2015. Interspecific potato somatic hybrids between Solanum tuberosum and S. cardiophyllum, potential sources of late blight resistance breeding. Plant Cell Tissue and Organ Culture 123, 579-589. DOI 10.1007/s11240-015-0862-8

Chen HL, Wang LX, Wang SH, Liu CJ, Blair MW, Cheng XZ. 2015. Transcriptome sequencing of mung bean (Vigna radiate L.) genes and the identification of EST-SSR markers. Plos One 10, e0120273. DOI 10.1371/journal.pone.0120273

Christine HC, Franck C, Lydia MJS, Terence AB. 2013. Cytological characterisation of the underutilized forage crop Onobrychis viciifolia Scop. and other members of the Onobrychis genus. Genetic Resources and Crop Evolution 60:1987-1996. DOI 10.1007/s10722-013- 
9967-2

Duarte J, Rivière N, Baranger A, Aubert G, Burstin J, Cornet L. 2014. Transcriptome sequencing for high through put SNP development and genetic mapping in Pea. BMC Genomics 15, 126. DOI 10.1186/1471-2164-15-126

Frame, J. 2005. Forage legumes for temperate grasslands (pp. 309). Enfield, NH: FAO. Science Publishers Inc.

Garg R, Patel RK, Tyagi AK and Jain M. 2011. De novo assembly of chick pea transcriptome using short reads for gene discovery and marker identification. DNA Research 18, 53-63. DOI 10.1093/dnares/dsq028

Gupta PK and Varshney RK. 2000. The development and use of microsatellite markers for genetic analysis and plant breeding with emphasis on bread wheat. Euphytica 113, 163-185. DOI 10.1023/a:1003910819967

Gupta PK, Langridge $P$ and Mir RR. 2010. Marker-assisted wheat breeding: present status and future possibilities. Molecular Breeding 26, 145-161. DOI 10.1007/s11032-009-9359-7

Jena SN, Srivastava A, Rai KM, Ranjan A, Singh SK, Nisar T. 2012. Development and characterization of genomic and expressed SSRs for levant cotton (Gossypium herbaceum L.). Theoretical and Applied Genetics 124, 565-576. DOI 10.1007/s00122-011-1729-y

Jia XP, Deng YM, Sun XB, Liang LJ, and Ye XQ. 2015. Characterization of the global transcriptome using Illumina sequencing and novel microsatellite marker information in seashore paspalum. Genes and Genomics 37, 77-86. DOI 10.1007/s13258-014-0231-8

Kang YJ, Kim SK, Kim MY, Lestari P, Kim KH, Ha BK. 2014. Genome sequence of mungbean and insights into evolution within Vigna species. Nature Communications $\mathbf{5}$, 5443. DOI 10.1038/ncomms6443

Kaur S, Pembleton LW, Cogan NO, Savin KW, Leonforte T, Paull J. 2012. Transcriptome sequencing of field pea and faba bean for discovery and validation of SSR genetic markers. BMC Genomics 13, 104. DOI 10.1186/1471-2164-13-104

Kempf K, Mora-Ortiz M, Smith LM, Kolliker R and Skot L. 2016. Characterization of novel SSR markers in diverse sainfoin (Onobrychis viciifolia) germplasm. BMC Genetics 17, 124. DOI 10.1186/s12863-016-0431-0

Kfm S,Varshney RK, Röder MS and Börner A. 2010. EST-SSR based estimates on functional genetic variation in a barley (Hordeum vulgare L.) collection from Egypt. Genetic Resources and Crop Evolution 57, 515-521. DOI 10.1007/s10722-009-9489-0

Li CQ, Wang Y, Huang XM, Li J, Wang HC and Li JG. 2013. De novo assembly and characterization of fruit transcriptome in Litchi chinensis Sonn and analysis of differentially regulated genes in fruit in response to shading. BMC Genomics 14, 552. DOI 10.1186/14712164-14-552

Li HT, Chen X, Yang Y, Xu JS, Gu JX, Fu J. 2011. Development and genetic mapping of microsatellite markers from whole genome shotgun sequences in Brassica oleracea. Molecular Breeding 28, 585-596. DOI 10.1007/s11032-010-9509-y

Liu ZP, Chen TL, Ma LC, Zhao ZG, Zhao PX, Nan ZB. 2013a. Global transcriptome sequencing using the Illumina platform and the development of EST-SSR markers in 
autotetraploid alfalfa. Plos One 8, e83549. DOI 10.1371/journal.pone.0083549

Liu ZP, Liu GS and Yang QC. 2007. A novel statistical method for assessing SSR variation in autotetraploid alfalfa (Medicago sativa L.). Genetics and Molecular Biology 30, 2, 385-391. DOI org/10.1590/S1415-47572007000300015

Liu ZP, Ma LC, Nan ZB, and Wang YR. 2013b. Comparative transcriptional profiling provides insights into the evolution and development of the zygomorphic flower of viciaVicia sativa (Papilionoideae). Plos One 8, e57338. DOI 10.1371/journal.pone.0057338

Luo D, Zhou Q, Ma LC, Xie WG, Wang YR and Liu ZP. 2015. Novel polymorphic expressed-sequence tag-simple-sequence repeat markers in for genetic diversity analyses. Crop Science 55, 2712-2718. DOI 10.2135/cropsci2015.01.0012

Ma XF, Tudor S, Butler T, Ge YX, Xi YJ, Bouton J, Harrison M, Wang ZY. 2012. Transgenic expression of phytase and acid phosphatase genes in alfalfa (Medicago sativa) leads to improved phosphate uptake in natural soils. Molecular Breeding 30:377-391 DOI 10.1007/s11032-011-9628-0

Malisch CS, Luscher A, Baert N, Engstrom MT, Studer B, Fryganas C, Salminen JP. 2015. Large variability of proanthocyanidin content and composition in sainfoin (Onobrychis viciifolia). Journal of Agricultural and Food Chemistry 63, 10234-10242. DOI org/10.1021/acs.jafc.5b04946

Mora-Ortiz M, Swain MT, Vickers MJ, Hegarty MJ, Kelly R, Smith LM. 2016. De novo transcriptome assembly for gene identification, analysis, annotation, and molecular marker discovery in Onobrychis viciifolia. BMC Genomics 17, 756. DOI 10.1186/s12864-0163083-6

Nisar M, Khan A, Wadood SF, Shah AA and Hanci F. 2017. Molecular characterization of edible pea through EST-SSR markers. Turkish Journal of Botany 41, 338-346. DOI 10.3906/bot-1608-17

Ong WD, Voo CL and Kumar SV. 2012. Development of ESTs and data mining of pineapple EST-SSRs. Molecular Biology Reports 39, 5889-5896. DOI 10.1007/s11033-011-1400-3

Pan L, Xia QJ, Quan ZW, Liu HG, Ke WD and Ding Y. 2010. Development of novel ESTSSRs from sacred lotus (Nelumbon ucifera Gaertn) and their utilization for the genetic diversity analysis of N. nucifera. Journal of Heredity 101, 71. DOI 10.1093/jhered/esp070

Parker RJ and Moss BR. 1981. Nutritional value of sainfoin hay compared with alfalfa hay 1. Journal of Dairy Science 64, 206-210. DOI 10.3168/jds.S0022-0302 (81) 82555-6

Prasanna BM, Pixley K, Warburton ML, Xie CX, Gupta PK, Balyan HS. 2010. Molecular marker-assisted breeding options for maize improvement in Asia. Molecular Breeding 26, 339-356. DOI 10.3168/jds.S0022-0302 (81)82555-6

Qiu L, Yang C, Bo T, Yang JB and Liu A. 2010. Exploiting EST databases for the development and characterization of EST-SSR markers in castor bean (Ricinuscommunis L.). BMC Plant Biology 10, 278. DOI 10.1186/1471-2229-10-278

Scharenberg A, Arrigo Y, Gutzwiller A, Wyss U, Hess HD, Kreuzer M. 2007. Effect of feeding dehydrated and ensiled tanniferous sainfoin (Onobrychis viciifolia) on nitrogen and mineral digestion and metabolism of lambs. Archives of Animal Nutrition 61, 390. DOI 


\section{$10.1080 / 17450390701565081$}

Schmutz J, Cannon SB, Schlueter J, Ma J, Mitros T, Nelson W. 2009. Genome sequence of the palaeopolyploid soybean. Nature 463, 178-183. DOI 10.1038/nature08670

Schmutz J, Mcclean PE, Mamidi S, Wu GA, Cannon SB, Grimwood J. 2014. A reference genome for common bean and genome-wide analysis of dual domestications. Nature Genetics 46, 707-713. DOI 10.1038/nature08670

Sipahi H, Sipahi H, Baum M, Baum M and Baum M. 2017. Construction of new EST-SSRs for Fusarium resistant wheat breeding. Computational Biology and Chemistry 68, 22. DOI10.1016/j.compbiolchem

Sottie ET, Acharya SN, McAllister T, Thomas J, Wang Y \& Iwaasa A. 2014. Alfalfa pasture bloat can be eliminated by intermixing with newly-developed sainfoin population. Agronomy Journal 106, 1470-1478. DOI org/10.2134/agronj13.0378

Sun GL, Salomon B and Bothmer RV. 2002. Microsatellite polymorphism and genetic differentiation in three Norwegian populations of Elymus alaskanus (Poaceae). Plant Systematics and Evolution 234, 101-110. DOI 10.1007/s00606-002-0211-3

Surendra B, Bruce C, Aaron DB, Bill B. 2018. Assessment of sainfoin (Onobrychis viciifolia Scop.) germplasm for agro-morphological traits and nutritive value. Grass and Forage Science 73:958-966. DOI 10.1111/gfs.12372

Tan LQ, Wang LY, Wei K, Zhang CC, Wu LY, Qi GN. 2013. Floral transcriptome sequencing for SSR marker development and linkage map construction in the tea plant (Camellia sinensis). Plos One 8, e81611. DOI 10.1371/journal.pone.0081611

Thiel T, Michalek W, Varshney RK and Graner A. 2003. Exploiting EST databases for the development and characterization of gene-derived SSR-markers in barley (Hordeum vulgare L.). Theoretical and Applied Genetics 106, 411-422. DOI 10.1007/s00122-0021031-0

Varshney RK, Graner A and Sorrells ME. 2005. Genic microsatellite markers in plants: features and applications. Trends Biotechnol 23, 48. DOI 10.1016/j.tibtech.2004.11.005

Wang SF, Wang XF, He QW, Liu XX, Xu WL, Li LB. 2012. Transcriptome analysis of the roots at early and late seedling stages using Illumina paired-end sequencing and development of EST-SSR markers in radish. Plant Cell Reports 31, 1437-1447. DOI 10.1007/s00299-012-1259-3

Wang ZY, Fang BP, Chen JY, Zhang XJ, Luo ZX, Huang LF. 2010. De novo assembly and characterization of root transcriptome using Illumina paired-end sequencing and development of cSSR markers in sweet potato (Ipomoea batatas). BMC Genomics 11, 726. DOI 10.1186/1471-2164-11-726

Wei WL, Qi XQ, Wang LH, Zhang YX, Wei H, Li DH. 2011. Characterization of the sesame (Sesamumindicum L.) global transcriptome using Illumina paired-end sequencing and development of EST-SSR markers. BMC Genomics 12, 451. DOI 10.1186/1471-2164-12451

Wu J, Cai CF, Cheng FY, Cui HL and Zhou H. 2014. Characterisation and development of EST-SSR markers in tree peony using transcriptome sequences. Molecular Breeding 34, 
504

505

506

507

508

509

510

511

512

513

514

515

516

517

518

519

520

521

522

523

1853-1866. DOI 10.1007/s11032-014-0144-x

Yang JK, Satyawan D, Shim S, Lee T, Lee J, Hwang WJ. 2015. Draft genome sequence of adzuki bean, Vignaangularis. Scientific Reports 5, 8069. DOI 10.1038/srep08069

Yang ZJ, Peng ZS and Yang H. 2016. Identification of novel and useful EST-SSR markers from de novo transcriptome sequence of wheat (Triticum aestivum L.). Genetics and Molecular Research 19;15(1). DOI 10.4238/gmr.15017509

Yates SA, Swain MT, Hegarty MJ, Chernukin I, Lowe M, Allison GG. 2014. De novo assembly of red clover transcriptome based on RNA-Seq data provides insight into drought response, gene discovery and marker identification. BMC Genomics 15, 453. DOI 10.1186/1471-2164-15-453

Young ND, Oldroyd GED, Geurts R, Cannon SB, Udvardi MK, Benedito VA. 2011. The Medicago genome provides insight into the evolution of rhizobial symbioses. Nature. $\mathbf{4 8 0}$, 520-524. DOI 10.1038/nature10625

Zhang JX, Wu KL, Zeng SJ, Silva JATD, Zhao XL, Tian CE. 2013. Transcriptome analysis of Cymbidium sinense and its application to the identification of genes associated with floral development. BMC Genomics 14, 279. DOI 10.1186/1471-2164-14-279

Zhou Q, Luo D, Ma LC, Xie WG, Wang YR and Liu ZP. 2016. Development and crossspecies transferability of EST-SSR markers in Siberian wildrye (Elymussibiricus L.) using Illumina sequencing. Scientific Reports. 6, 20549. DOI 10.1038/srep20549 
524

525

526

527

528

529

530

531

532

533

534

535

536

537

538

539

540

541

542

543

544

\section{FIGURE LEGENDS}

Figure 1. Tissues used in this study. Samples were collected as described in the Materials

and Methods section. (A) Callus cells. (B) An emerging tidbit. (C) A young inflorescence. (D)

An inflorescence. (E) Mature inflorescence. (F) Developing seed pods. (G) Mature seed pods.

(H) Roots. (I) A germinated seed. (J) Young stems. (K) Stems. (L) Mature stems. (M) A young compound leaf. (N) A mature compound leaf. Bar $=1 \mathrm{~cm}$.

Figure 2. Phylogenic relationships among the 40 wild sainfoin individuals. The phylogeny tree was constructed using a neighbor-joining dendrogram in the Darwin software. The starting dataset was represented by the 61 best EST-SSRs. I-V, group number representing five different sampling locations. 1-8, sample number representing eight individual samples in the same group.

Figure 3. STRUCTURE analysis of the genetic structures of five vetch sainfoin. Six different colors represent six different clusters. (A) Pink, cluster 1; Green, cluster 2; Cyan, cluster 3; Blue, cluster 4; Yellow, cluster 5; and Red, cluster 6. (B) The value of the predicted population size $(\Delta \mathrm{k})$. Genetic structure of eight individuals in each of the five sainfoin sample populations is inferred by STRUCTURE using the EST-SSR markers dataset.

Figure 4. Comparative analysis of the DNA fragment peak spectrum for two selected ESTSSR loci among the same unit of Onobrychis viciifolia. (A) Vo61selected individual from II-2. (B) Vo157 selected individual from II-1.

\section{TABLE LEDGES}

Table1. Summary of the de novo assembled sainfoin EST-SSRs. 
545 Table 2. Functional annotation of sainfion transcriptome.

546 Table 3 Length distribution of EST-SSRs determined by the number of nucleotide repeats.

547 ADDITIONAL FILES

548 Supplementary Table S1. Detailed information of EST-SSRs based on the number of

549 nucleotide repeat units.

550 Supplementary Table S2. Analysis of 200 primer pairs.

551 Supplementary Table S3. Sampling of sainfoin for marker validation assays.

552 Supplementary Table S4. Primer pairs used to analyze the 61 developed EST-SSR markers

553 in sainfoin.

554 Supplemental Table S5. The types and distributions potential EST-SSRs.

555 Supplemental Table S6. Population analysis data in the structure.

556 Supplementary Figure S1. Length distribution of all unigenes. The x-axis represents the size

557 of all unigenes, and the y-axis represents the number of unigenes within a certain range of length.

558 Supplementary Figure S2. COG analysis of the unigene sequences. The y-axis indicates the

559 number of unigenes in a specific functional cluster. A-Z and different colors indicate different

560 COG categories.

561 Supplementary Figure S3. Summary of GO analysis of the unigene sequences. The y-axis

562 on the right indicates the number of genes in a category. The y-axis on the left indicates the

563 number of genes in a specific category.

564 Supplementary Figure S4. Statistics on the density distribution of different types of EST-

565 SSR. 
566 Supplementary Figure S5. Gene ontology (GO) term enrichment status for SSR repeat-

567 containing unigenes in sainfoin. (A) Biological process. (B) Cellular component. (C) Molecular

568 function. (D) legend. The color scale shows the p-value cut-off levels for each biological

569 (Cellular) process. A deeper color denotes a more significant biological pathway.

570 Supplementary Figure S6. Variations of EST-SSR markers by PCR using the PCR primer

571 set Vo61 and Vo157 and the 40 wild sainfoin individuals collected from the five different

572 geographic locations. The letter $M$ denotes a molecular marker of 300 and $200 \mathrm{bp}$ size (top to

573 bottom). The red triangle indicates the individual plant used to cut the polyacrylamide gel,

574 Vo61selected No. 2 individual from site 2, Vo157 selected No.1 individual from site 2. 


\section{Figure 1}

Tissues used in this study. Samples were collected as described in the Materials and Methods section.

(A) Callus cells. (B) An emerging tidbit. (C) A young inflorescence. (D) An inflorescence. (E) Mature inflorescence. (F) Developing seed pods. (G) Mature seed pods. (H) Roots. (I) A germinated seed. (J) Young stems. (K) Stems. (L) Mature stems. (M) A young compound leaf. (N) A mature compound leaf. Bar $=1 \mathrm{~cm}$.

*Note: Auto Gamma Correction was used for the image. This only affects the reviewing manuscript. See original source image if needed for review.
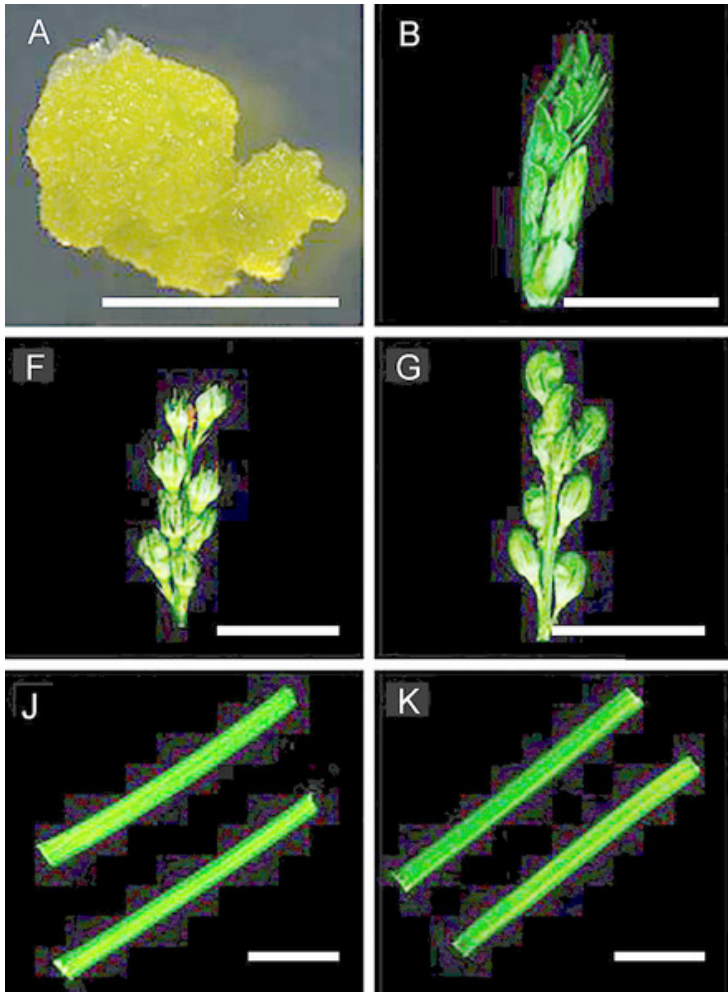
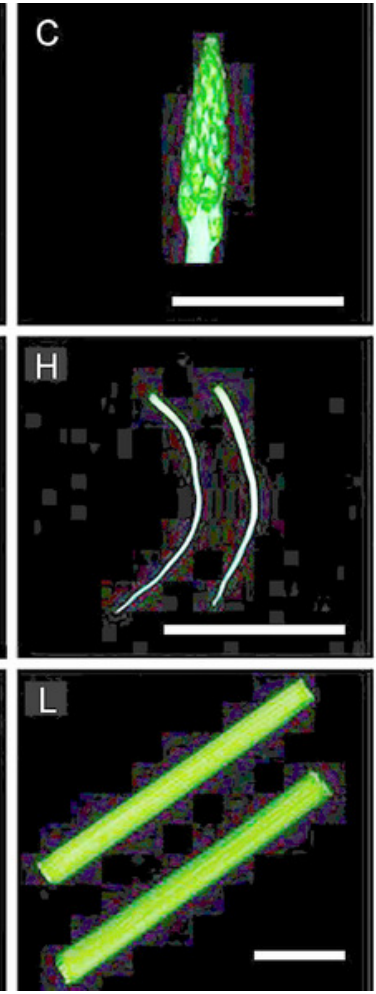
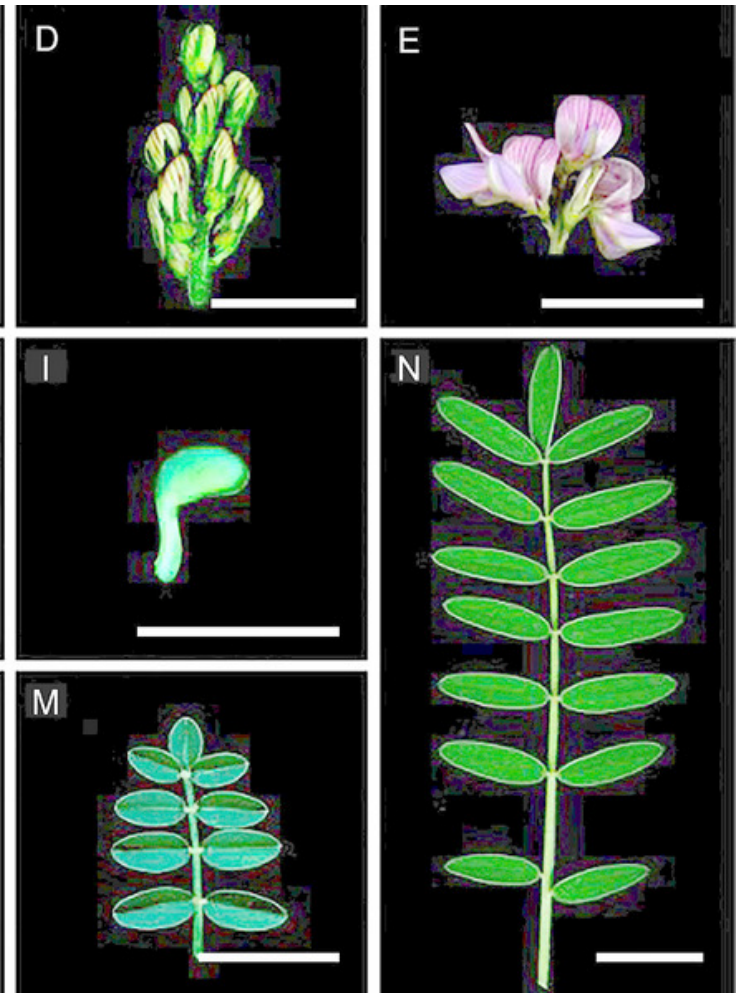
Figure 2

Phylogenic relationships among the 40 wild sainfoin individuals. The phylogeny tree was constructed using a neighbor-joining dendrogram in the Darwin software.

The starting dataset was represented by the 61 best EST-SSRs. I-V, group number representing five different sampling locations. 1-8, sample number representing eight individual samples in the same group. 


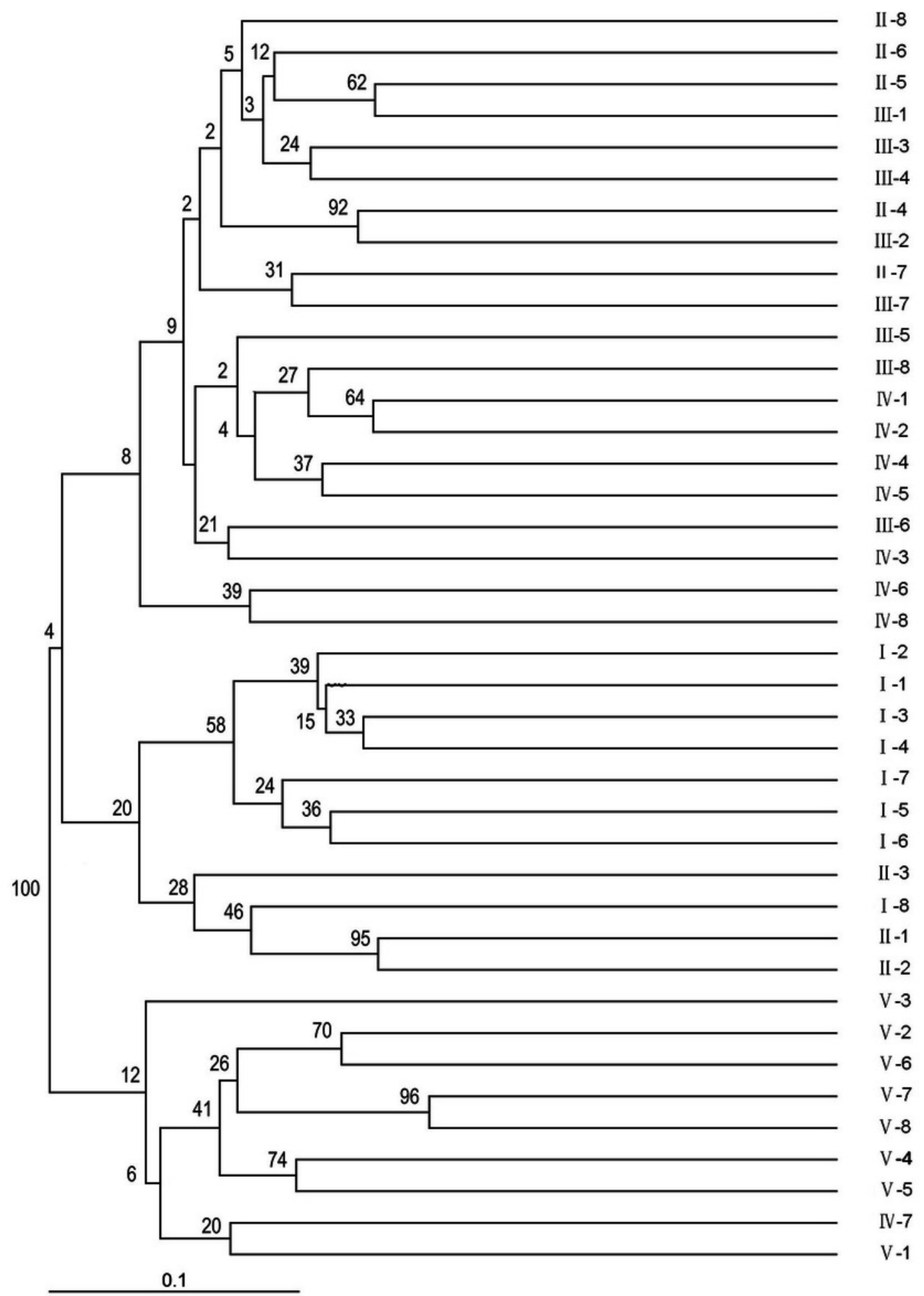


Figure 3

STRUCTURE analysis of the genetic structures of five vetch sainfoin.

Six different colors represent six different clusters. (A) Pink, cluster 1; Green, cluster 2; Cyan, cluster 3; Blue, cluster 4; Yellow, cluster 5; and Red, cluster 6. (B) The value of the predicted population size $(\Delta \mathrm{k})$. Genetic structure of eight individuals in each of the five sainfoin sample populations is inferred by STRUCTURE using the EST-SSR markers dataset.
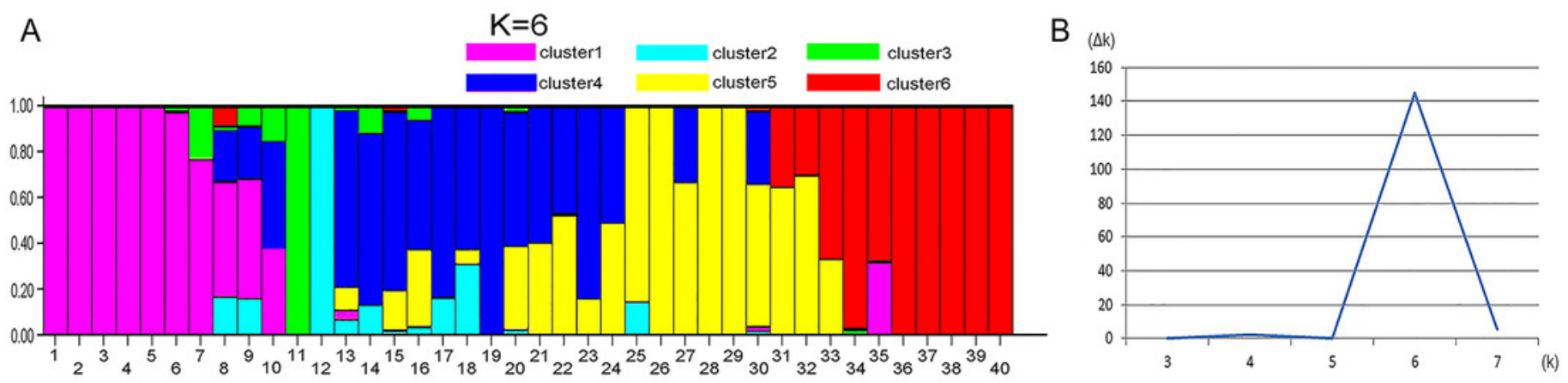
Figure 4

Comparative analysis of the DNA fragment peak spectrum for two selected EST-SSR loci among the same unit of Onobrychis viciifolia.

(A) Vo61selected individual from II -2. (B) Vo157 selected individual from II -1.
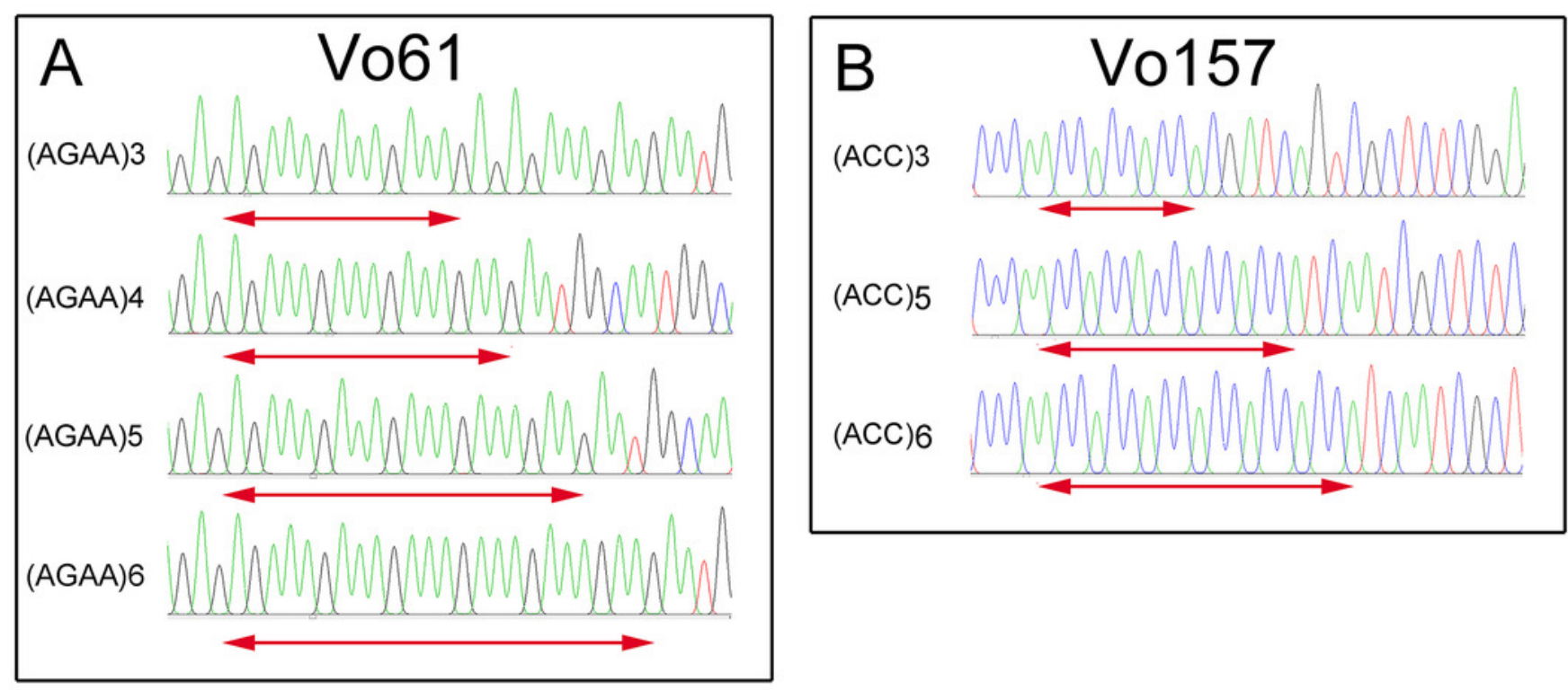


\section{Table 1 (on next page)}

Summary of the de novo assembled sainfoin EST-SSRs. 
1 Table1 Summary of the de novo assembled sainfoin EST-SSRs.

\begin{tabular}{|c|c|c|}
\hline Category & Items & Number \\
\hline Raw Reads & Total Raw Reads & $26,912,927$ \\
\hline \multirow{5}{*}{ Clean Reads } & Total Clean Reads & $24,630,711$ \\
\hline & Total Clean Nucleotides (nt) & $6,264,706,761$ \\
\hline & Q30 Percentage & $91.52 \%$ \\
\hline & N Percentage & $0 \%$ \\
\hline & GC Percentage & $44.98 \%$ \\
\hline \multirow{4}{*}{ Contigs } & Total Number & $2,678,687$ \\
\hline & Total Length (bp) & $193,558,725$ \\
\hline & Mean Length (bp) & 72.26 \\
\hline & N50 (bp) & 69 \\
\hline \multirow{6}{*}{ Unigenes } & Total Number & 77,764 \\
\hline & Total Length (bp) & $53,035,704$ \\
\hline & Mean Length (bp) & 682.01 \\
\hline & N50 (bp) & 1,209 \\
\hline & Distinct Clusters & 27,437 \\
\hline & Distinct Singletons & 50,327 \\
\hline \multirow{4}{*}{ EST-SSRs } & Total Number of Examined Sequences & 77,764 \\
\hline & Total Number of Identified SSRs & 6,752 \\
\hline & Number of SSR-Containing Sequences & 4,988 \\
\hline & $\begin{array}{l}\text { Number of Sequences Containing More } \\
\text { Than One SSR }\end{array}$ & 1,271 \\
\hline
\end{tabular}

2 
Table 2 (on next page)

Functional annotation of sainfion transcriptome. 
1 Table 2 Functional annotation of sainfion transcriptome.

\begin{tabular}{lcl}
\hline Category & Number & Percentage (\%) \\
\hline Nr annotation & 35,421 & $46 \%$ \\
KOG Annotation & 19,555 & $25 \%$ \\
Pfam Annotation & 24,282 & $31 \%$ \\
Swiss-pro Annotation & 21,973 & $28 \%$ \\
KEGG annotation & 11,923 & $15 \%$ \\
COG annotation & 10,387 & $13 \%$ \\
GO annotation & 22,237 & $29 \%$ \\
All & 36,353 & $47 \%$ \\
\hline
\end{tabular}

2 


\section{Table 3 (on next page)}

Length distribution of EST-SSRs determined by the number of nucleotide repeats. 
1 Table 3 Length distribution of EST-SSRs determined by the number of nucleotide repeats.

\begin{tabular}{|c|c|c|c|c|c|c|c|c|}
\hline $\begin{array}{l}\text { Number of } \\
\text { repeats }\end{array}$ & Mono- & Di- & Tri- & Quad- & Penta- & Hexa- & Total & $\begin{array}{l}\text { Percentage } \\
(\%)\end{array}$ \\
\hline 5 & 0 & 0 & 1,430 & 231 & 10 & 9 & 1,680 & 24.88 \\
\hline 6 & 0 & 474 & 626 & 31 & 4 & 5 & 1,140 & 16.88 \\
\hline 7 & 0 & 287 & 191 & 0 & 1 & 0 & 479 & 7.09 \\
\hline 8 & 0 & 204 & 15 & 1 & 0 & 1 & 221 & 3.27 \\
\hline 9 & 0 & 138 & 0 & 0 & 0 & 3 & 141 & 2.09 \\
\hline 10 & 1,370 & 120 & 0 & 0 & 0 & 0 & 1,490 & 22.07 \\
\hline 11 & 627 & 60 & 0 & 0 & 0 & 1 & 688 & 10.19 \\
\hline 12 & 270 & 4 & 0 & 0 & 0 & 0 & 274 & 4.06 \\
\hline 13 & 218 & 0 & 0 & 0 & 0 & 0 & 218 & 3.23 \\
\hline 14 & 152 & 0 & 0 & 0 & 0 & 0 & 152 & 2.25 \\
\hline 15 & 112 & 0 & 0 & 0 & 0 & 0 & 112 & 1.66 \\
\hline 16 & 76 & 0 & 0 & 0 & 0 & 0 & 76 & 1.13 \\
\hline 17 & 41 & 0 & 0 & 0 & 0 & 0 & 41 & 0.61 \\
\hline 18 & 11 & 0 & 0 & 0 & 0 & 0 & 11 & 0.16 \\
\hline 19 & 8 & 0 & 0 & 0 & 0 & 0 & 8 & 0.12 \\
\hline 20 & 2 & 0 & 0 & 0 & 0 & 0 & 2 & 0.03 \\
\hline 21 & 9 & 0 & 0 & 0 & 0 & 0 & 9 & 0.13 \\
\hline 22 & 5 & 0 & 0 & 0 & 0 & 0 & 5 & 0.07 \\
\hline 23 & 4 & 0 & 0 & 0 & 0 & 0 & 4 & 0.06 \\
\hline 24 & 1 & 0 & 0 & 0 & 0 & 0 & 1 & 0.01 \\
\hline
\end{tabular}




\begin{tabular}{lllllllll} 
Total & 2,906 & 1,287 & 2,262 & 263 & 15 & 19 & 6,752 & - \\
$\begin{array}{l}\text { Percentage } \\
(\%)\end{array}$ & 43.04 & 19.06 & 33.50 & 3.90 & 0.22 & 0.28 & - & - \\
\hline
\end{tabular}

2 